Rev. Bras. Saúde Prod. Anim., Salvador, v.16, n.2, p.430-439 abr./jun.., 2015 http://www.rbspa.ufba.br

\title{
Probiótico na alimentação de pós-larvas de tilápias-do-nilo submetidas a desafio sanitário
}

\author{
Probiotics in feed of post- larvae of Nile tilapia subjected to sanitary challenge
}

\author{
FERREIRA, Antônio Hosmylton Carvalho ${ }^{1 *}$; BRITO, Johnny Martins de ${ }^{2}$; LOPES, \\ João Batista ${ }^{3}$; SANTANA JÚNIOR, Hermógenes Almeida de ${ }^{4}$; BATISTA, João Marcos \\ Monteiro $^{4}$; SILVA, Bruna Rocha ${ }^{4}$; SOUZA, Ezequiel Marques ${ }^{4}$; AMORIM, Igor Luan \\ de Souza ${ }^{4}$
}

\author{
${ }^{1}$ Universidade Estadual do Piauí, Campus Professor Alexandre Alves de Oliveira, Curso de Agronomia, \\ Parnaíba, Piauí, Brasil. \\ ${ }^{2}$ Universidade Federal do Piauí, Campus Professora Cinobelina Alves, Bom Jesus, Piauí, Brasil. \\ ${ }^{3}$ Universidade Federal do Piauí, Campus de Teresina, Departamento de Zootecnia, Piauí, Brasil. \\ ${ }^{4}$ Universidade Estadual do Piauí, Campus Jesualdo Cavalcante, Curso de Zootecnia, Corrente; Piauí; Brasil. \\ *Endereço para correspondência: hosmylton@hotmail.com
}

\section{RESUMO}

Objetivou-se avaliar o efeito da cepa probiótica Saccharomy cerevisiae na alimentação de póslavas de tilápias-do-nilo submetidas a desafio sanitário (fezes de ovinos). Foram selecionadas 300 pós-larvas, com média de peso e comprimentos uniformes. Os tratamentos consistiram de peixes cultivados em água limpa com ração comercial, em quantidade de $10 \%$ da biomassa, sem o uso de probiótico e peixes cultivados em água sob desafio sanitário, alimentados com ração comercial, em quantidade de $10 \%$ da biomassa e com o uso de probiótico $\left(1,0 \mathrm{~g} \mathrm{Kg}^{-1}\right)$. Para promover o desafio sanitário aos peixes, foram dissolvidos $50 \mathrm{~g}$ de fezes de ovinos trituradas in natura em $1000,0 \mathrm{~mL}$ de água. Foram avaliadas as variáveis da qualidade da água para determinação imposta pelos dois tratamentos experimentais. Constatou-se efeito significativo $(\mathrm{P}<0,05)$ na concentração de fósforo total, $\mathrm{pH}$ e oxigênio dissolvido da água com fezes de ovinos, representando o desafio do meio, fato este essencial para a realização desse experimento. Não houve efeito significativo $(\mathrm{P}>0,05)$ nas variáveis de desempenho, sobrevivência e índice hepatosomático. As pós-larvas de tilápias-do-nilo alimentadas com ração contendo probiótico $\left(1 \mathrm{~g} . \mathrm{kg}^{-1}\right)$ submetidas a desafio sanitário proporcionam melhorias no desempenho, sobrevivência e índice hepatossomático equiparando-se aos peixes de água limpa sem o uso de probiótico.

Palavras-chave: ambiente, consumo, desempenho, piscicultura

\section{SUMMARY}

This study aimed to evaluate the effect of the probiotic Saccharomyces cerevisiae in feeding post-lavas of Nile tilapia subjected to sanitary challenge (sheep feces). 300 post-larvae were selected, with average weight and uniform lengths. The treatments consisted of fish grown in commercial feed with clean water, in an amount of $10 \%$ of the biomass, without the use of probiotics and fish grown in water under sanitary challenge fed with commercial diet at $10 \%$ of the amount of biomass and the use of probiotics $\left(1.0 \mathrm{~g} \mathrm{~kg}^{-1}\right)$. To promote the health challenge the fish were dissolved $50 \mathrm{~g}$ of feces in sheep nature crushed in $1000.0 \mathrm{ml}$ of water. Variables of water quality to determine imposed by the two experimental treatments were evaluated. A significant effect $(\mathrm{P}<0.05)$ in the concentration of total phosphorus, $\mathrm{pH}$ and dissolved oxygen water with sheep faeces, representing half of the challenge, a fact essential to conduct this experiment. There was no significant effect $(\mathrm{P}>0.05)$ in performance variables, survival and hepato-somatic index. Post-larvae of Nile tilapia fed diet containing probiotic (1g.kg-1) submitted to health challenge provide improvements in performance, survival and liver somatic index matching up to clean water fish without using probiotic.

Keywords: consumption, environment, performance, pisciculture 
Rev. Bras. Saúde Prod. Anim., Salvador, v.16, n.2, p.430-439 abr./jun.., 2015 http://www.rbspa.ufba.br

\section{INTRODUÇÃO}

Dados estatísticos do Ministério da Pesca e Aquicultura confirmam que a produção nacional de pescado no ano de 2010 foi de 1.264 mil toneladas, sendo $62 \%$ originados da pesca e os outros $38 \%$ provenientes da aquicultura (BRASIL, 2012). Dentre as espécies, a tilápia-do-nilo é considerada como de grande potencial no país (BORGUETTI et al., 2003).

Assim como em qualquer outra atividade, a ocorrência de enfermidades deve ser controlada de imediato, uma vez que o meio aquoso favorece a disseminação de microrganismos e em especial os patogênicos (GATESOUPE, 2008). O aumento de problemas ocasionados por doenças leva a perda significativa na produção aquícola, afetando o desenvolvimento econômico do setor (GRAM et al., 2009).

$\mathrm{O}$ uso dos probióticos na aquicultura, vem sendo utilizado na perspectiva de substituírem os antibióticos. No entanto, os resultados apresentados têm sido contraditórios em virtude dos animais, na maioria das vezes apresentarem excelentes condições sanitárias, inclusive, existindo empreendimentos livres de patógenos, em que essas condições não permitem avaliar a eficiência dos probióticos ou de produtos similares (SANTOS et al., 2009a). Por outro lado, quando os animais são submetidos a desafios sanitários, os resultados das pesquisas são promissores (MONTEIRO et al., 2011). Assim, os probióticos, que são formados por micro-organismos vivos que atuam sobre o animal de modo a favorecê-lo em seu estado de saúde, vem apresentando resultados positivos no cultivo de peixes (BALCAZAR et al., 2008; BORQUEZ et al., 2010; DHARMARAJ et al., 2010;
GATESOUPE et al., 2008; GRAM et al., 2009).

O esterco de ovino é um adubo bastante rico e que pode ser utilizado na piscicultura no intuito de melhorar a qualidade da água do cultivo. Dentro do grupo dos animais ruminantes, os ovinos são aqueles que apresentam uma alta concentração de nitritos nas fezes, por ser extremamente concentrada, sendo assim, pode ocasionar dependendo da quantidade utilizada no ambiente aquícola, o desafio sanitário aos animais. Portanto, apesar de seu efeito benéfico sobre o alimento natural dos viveiros, o esterco de ovino pode conter microrganismos patogênicos e proporcionar dificuldades ao peixes.

Avaliou-se o efeito do probiótico $(S$. cerevisiae) na alimentação de pós-lavas de tilápias-do-nilo submetidas a um desafio sanitário (fezes de ovinos) sobre as variáveis de desempenho, sobrevivência e índice hepato-somático.

\section{MATERIAL E MÉTODOS}

O experimento foi realizado na Universidade Estadual do Piauí/UESPI, Campus Dep. Jesualdo Cavalcanti Barros/Corrente/PI, no Laboratório Experimental de Piscicultura (LEPIS).

Para montagem deste experimento foram adquiridas 600 pós-larvas de tilápias-do-nilo, que foram estocados durante três dias numa caixa d'água de 310 litros, recebendo oxigenação (compressores de ar), renovação de água e alimentação periódica.

Do total de peixes, foram selecionadas 300 pós-larvas (Oreochromis niloticus), peso inicial médio de $0,72 \pm 0,05 \mathrm{~g}$ e comprimento inicial médio de $3,40 \pm$ $0,35 \mathrm{~cm}$. Foram distribuídas em 20 caixas com capacidade de 100 litros e ficaram por 24 horas, para adaptação às 
Rev. Bras. Saúde Prod. Anim., Salvador, v.16, n.2, p.430-439 abr./jun.., 2015 http://www.rbspa.ufba.br ISSN 15199940

condições impostas pelo meio. Utilizouse o delineamento inteiramente casualizado, com dois tratamentos e dez repetições. A unidade experimental consistiu em uma caixa com quinze póslavas de tilápias-do-nilo. O período experimental teve duração de 30 dias.

Os tratamentos consistiram de peixes cultivados em água limpa com ração comercial, ofertada em quantidade de $10 \%$ da biomassa, sem o uso de probiótico e peixes cultivados em água sob desafio sanitário (fezes de ovinos), alimentados com ração comercial, em quantidade de $10 \%$ da biomassa, com o uso de probiótico $\left(1,0 \mathrm{~g} \cdot \mathrm{Kg}^{-1}\right)$. Todos os tratamentos receberam aeração usando um sistema air-lift.

A água utilizada no experimento foi proveniente da rede municipal de abastecimento da cidade de Corrente/PI, em que a mesma era armazenada diariamente numa caixa d'água de 310 litros, para controlar os níveis de cloro e que possa abastecer com a quantidade de água necessária para cada repetição após a sifonação das caixas.

O probiótico utilizado possuía cepa única, a levedura Saccharomyces cerevisiae, juntamente com a presença de premix mineral e vitamínico como substrato. Foi utilizado 1,0g de probiótico, para cada quilograma de ração comercial $(35 \%$ de $\mathrm{PB})$. O produto em pó foi adicionado diretamente na ração, para ser feita a homogeneização (mistura). Esperou-se de cinco a dez minutos, de acordo com as recomendações do fabricante, para ocorrer à fixação das cepas. Logo após, a ração foi armazenada e pesada diariamente, sendo fornecida de acordo com a biomassa dos animais.

Foi utilizada uma ração comercial ${ }^{\circledR}$ de $35 \%$ PB e $3200 \mathrm{kcal} . \mathrm{kg}^{-1}$ de energia digestível (ED), sendo a recomendada de acordo com a fase de vida dos animais. $\mathrm{O}$ arraçoamento foi dividido em quatro refeições durante o dia $(07 \mathrm{~h} 00 ; 11 \mathrm{~h} 00 ; 14 \mathrm{~h} 00$ e às $17 \mathrm{~h} 00$ horas).

A ração comercial ${ }^{\circledR}$ apresentava como ingredientes bases: milho moído, farelo de soja, farelo de trigo, farinha de penas, farinha de carne, gordura animal, calcário calcítico, cloreto de sódio (sal comum), cloreto de colina, iodeto de cálcio, monóxido de manganês, óxido de zinco, premix mineral e vitamínico, conforme informações no rótulo do produto (Tabela 1 ).

Tabela 1. Composição centesimal da ração comercial ${ }^{\circledR}$ para pós-larvas de tilápias-donilo conforme informações no rótulo do produto

\begin{tabular}{|c|c|}
\hline Parâmetros nutricionais & Valores \\
\hline Proteína bruta (\%) & 35,0 \\
\hline Umidade (\%) & 13,0 \\
\hline Extrato etéreo (\%) & 5,0 \\
\hline Matéria Fibrosa (\%) & 7,0 \\
\hline Matéria mineral (\%) & 12,0 \\
\hline Cálcio & 3,0 \\
\hline Fósforo & 8,0 \\
\hline Pantotenato de cálcio & 4,0 \\
\hline \multicolumn{2}{|c|}{ 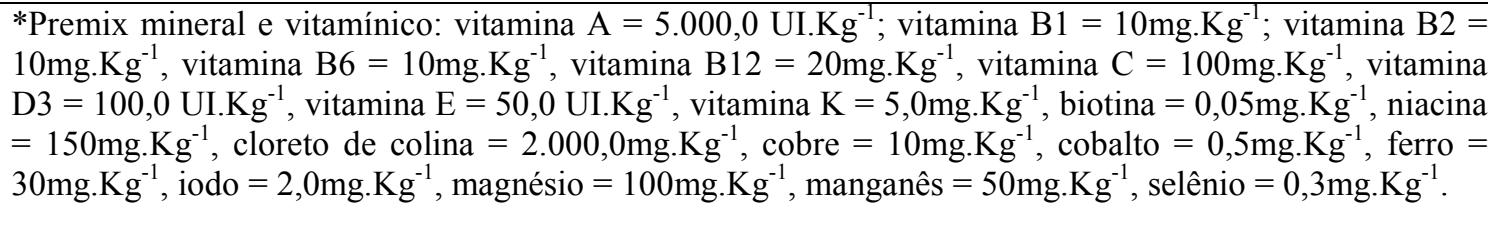 } \\
\hline
\end{tabular}


Para promover o desafio sanitário aos peixes, foram dissolvidos $50 \mathrm{~g}$ de fezes de ovinos trituradas in natura em 1000,0mL de água. Logo após a sifonagem diária foi adicionada $30,0 \mathrm{~mL}$ dessa mistura a cada unidade experimental durante $\mathrm{o}$ período $\mathrm{da}$ manhã. $\mathrm{O}$ esterco de ovino foi adquirido de propriedades do município de Corrente/PI.

A determinação da qualidade da água nos tratamentos avaliados foi realizada por meio da aferição de quatro parâmetros fundamentais dentro de um ambiente aquícola: o pH, oxigênio dissolvido, temperatura e o teor de fósforo total. As análises do fósforo total e $\mathrm{pH}$ foram realizadas no Laboratório de solos da Universidade Estadual do Piauí/UESPI, em que foram determinados por colorimetria e potenciômetro com eletrodo combinado respectivamente (EMBRAPA, 1997). Já o oxigênio dissolvido e a temperatura foram por meio de oxímetro digital.

Diariamente, pela manhã $(07 \mathrm{~h} 00)$ e à tarde (17h00), as caixas foram sifonados para retirada de fezes e restos de ração, com remoção padronizada de aproximadamente $10 \%$ da água nos 30 dias de experimento.

No final do período experimental os peixes foram mantidos em jejum por 24 horas, sendo retirados, aleatoriamente, dois peixes de cada repetição para sacrifício por hiportemia, de acordo com os princípios éticos de abate dos animais. $\mathrm{O}$ projeto foi analisado por um comitê de ética local conforme carta de aprovação $\mathrm{n}^{\circ} 011 / 12$.

Foi realizada uma incisão na região abdominal, retirando-se as vísceras, separando o fígado para determinação do índice hepato-somático. Para tal determinação pesou-se a massa corpórea individual do peixe e a massa do fígado para a realização do calculo do índice hepato-somático (IHS) $=(($ peso do fígado/peso corporal) $\times 100$ ) .

Os peixes foram pesados e medidos no início e final do experimento para a determinação dos seguintes parâmetros zootécnicos: ganho em peso diário $(\mathrm{GPD})=($ peso final - peso inicial) / tempo (em dias); consumo diário de ração $(\mathrm{CDR})=$ consumo de alimento / tempo (em dias); conversão alimentar aparente $(\mathrm{CAA})=$ consumo de alimento / ganho em peso total; ganho de crescimento diário $\mathrm{GCd}=$ (crescimento final crescimento inicial)/dias; sobrevivência $(\mathrm{S})=100 *\left(\mathrm{~N}^{\circ}\right.$ inicial de peixes $-\mathrm{N}^{\circ}$ final de peixes) / $\mathrm{N}^{\circ}$ inicial de peixes. A ração foi fornecida todos os dias nos horários determinados sendo de acordo com a necessidade dos peixes, e ao término do dia foram contabilizadas as sobras.

Foram determinados $\mathrm{o}$ também $\mathrm{o}$ consumo diário de proteína bruta $(\mathrm{CDPB})=(\mathrm{CDR} \times \% \mathrm{~PB}) / 100$ e a taxa de eficiência proteica $($ TEP) $=$ GP / CPB. Esses foram encontrados para comprovação do teor de proteína entre o tratamento controle e o experimental.

Os dados da qualidade da água e do desempenho dos animais foram submetidos à Análise variância (ANOVA), em que as médias foram comparadas pelo teste de Tukey a 5\% de probabilidade, utilizando o Statistical Analysis System (SAS, 2003).

\section{RESULTADOS E DISCUSSÃO}

Houve diferença significativa $(\mathrm{P}<0,05)$ na concentração de fósforo total, $\mathrm{pH}$ e oxigênio dissolvido (Tabela 2) da água de cultivo, sendo que no tratamento que foi utilizado probiótico os valores foram diferentes dos encontrados na água sem $\mathrm{o}$ uso de probiótico na ração. $\mathrm{O}$ desempenho de animais mantidos em 
Rev. Bras. Saúde Prod. Anim., Salvador, v.16, n.2, p.430-439 abr./jun.., 2015 http://www.rbspa.ufba.br ISSN 15199940

boas condições de manejo dificilmente é influenciado pela ingestão de probióticos (LIMA et al., 2003), pois nessas condições o contato de microrganismos é mínimo.

A concentração de fósforo encontrada no tratamento que representa o desafio nos animais foi bem superior aos encontrados por Santos et al. (2009b) ao avaliar o teor de fósforo total em esgoto doméstico tratado com o uso de aeradores $\left(3,5 \pm 1,95 \mathrm{mg} . \mathrm{L}^{-1}\right)$.

A concentração de OD foi bem inferior na água com desafio, sendo que a concentração ideal de oxigênio dissolvido para ótimo crescimento das espécies de peixes tropicais é de 58mg. L $^{-1} \quad$ (PROENÇA \& BITTENCOURT, 2004).

Tabela 2. Parâmetros de qualidade da água do cultivo de alevinos de tilápias-do-nilo submetidas ou não a desafio sanitário

\begin{tabular}{|c|c|c|}
\hline \multirow{2}{*}{ Parâmetros } & Água sem desafio sanitário & Água com desafio sanitário $\left(1 \mathrm{~g} \cdot \mathrm{kg}^{-1}\right)$ \\
\hline & \multicolumn{2}{|c|}{ Média \pm Desvio padrão } \\
\hline Fósforo total $\left(\mathrm{mg} . \mathrm{L}^{-1}\right)$ & $8,31 \pm 1,40^{\mathrm{b}}$ & $10,64 \pm 1,26^{\mathrm{a}}$ \\
\hline $\mathrm{pH}$ & $6,86 \pm 0,13^{\mathrm{a}}$ & $6,75 \pm 0,09^{\mathrm{b}}$ \\
\hline $\mathrm{OD}\left(\mathrm{mg} \cdot \mathrm{L}^{-1}\right)$ & $6,1 \pm 0,4^{\mathrm{a}}$ & $3,8 \pm 0,2^{\mathrm{b}}$ \\
\hline Temperatura $\left({ }^{\circ} \mathrm{C}\right)$ & $29,1 \pm 1,1^{\mathrm{a}}$ & $28,5 \pm 1,0^{\mathrm{a}}$ \\
\hline
\end{tabular}

$\mathrm{pH}=$ potencial hidrogeniônico; $\mathrm{OD}=$ oxigênio dissolvido.

${ }^{\mathrm{a}, \mathrm{b}}$ Médias seguidas de letras diferentes na mesma linha diferem estatisticamente pelo teste de Tukey a 5\% de significância $(\mathrm{P}<0,05)$.

Houve diferencia significativa $(\mathrm{P}<0,05)$ no $\mathrm{pH}$, em que a água com desafio apresentando-se mais ácida nos tanques onde se utilizou fezes de ovinos para o que colaborou para aumentar a quantidade de microrganismos na água e interferir na qualidade da mesma. A grande maioria dos peixes tropicais têm uma faixa ótima de $\mathrm{pH}$ de 6,5 a 9,0 (ZHOU et al., 2009). No entanto, quando esta faixa não se encontra dentro do ideal, ocorre que, os peixes apresentam crescimento lento e problemas na reprodução, inclusive podendo levar a morte desses animais. Abaixo de 4,5 e acima de 10,5 a mortalidade é significativa (KUBITZA, 2000).

Observa-se que os peixes que estavam no tratamento em que se utilizava o probiótico, estavam numa condição de estresse devido à alta concentração de fósforo, baixo $\mathrm{pH}$ e baixa concentração de oxigênio dissolvido (Tabela 2) na água de cultivo. Constata-se que a solução de fezes de ovinos que foi adicionada a água proporcionou desafio sanitário aos peixes, fato este essencial para a fundamentação da pesquisa.

Não houve efeito significativo $(\mathrm{P}>0,05)$ nas variáveis de desempenho (Tabela 3 ), observando-se que mesmo em condições adversas, os peixes se equipararam aos animais sem o uso de probiótico.

Os valores médios do consumo diário de ração (Tabela 3) não foram influenciadas $(\mathrm{P}>0,05)$ pelo desafio imposto ao meio aquático. Mesmo os peixes que estavam submetidos a uma elevada carga orgânica apresentaram um consumo equivalente ao controle. Possivelmente a utilização da cepa probiótica promoveu um melhor aproveitamento de nutrientes. Segundo Ai et al. (2011), as bactérias probióticas 
Rev. Bras. Saúde Prod. Anim., Salvador, v.16, n.2, p.430-439 abr./jun.., 2015 http://www.rbspa.ufba.br ISSN 15199940

atuam no hospedeiro melhorando a utilização dos alimentos, modulando a microbiota intestinal, estimulando a resposta imune e inibindo a colonização de patógenos no trato gastrointestinal melhorando o desempenho de peixes principalmente na fase inicial de vida dos animais.

Os animais que consumiram a ração com probiótico apresentaram um ganho de crescimento equivalente ao tratamento sem o uso. Kesarcodi et al. (2008) ressaltaram que, os probióticos em peixes são microrganismos vivos que podem servir como suplementos dietéticos para melhorar o crescimento e a resposta imune. Flores et al. (2003) estudaram a utilização de levedura e um probiótico comercial na dieta de larvas de tilápiasdo-nilo e os dois aditivos melhoraram significativamente $\mathrm{o}$ crescimento $\mathrm{em}$ relação a uma dieta controle.

Tabela 3. Desempenho de tilápias-do-nilo na fase de pós-larvas no período de 30 dias de cultivo submetidas a desafio sanitário com o uso de probiótico

\begin{tabular}{|c|c|c|c|c|}
\hline \multirow[t]{2}{*}{ Parâmetros } & $\begin{array}{l}\text { Ração sem } \\
\text { probiótico }\end{array}$ & $\begin{array}{l}\text { Ração com } \\
\text { probiótico }\end{array}$ & \multirow{2}{*}{$\begin{array}{l}\mathrm{CV} \\
(\%)\end{array}$} & \multirow[t]{2}{*}{$\mathrm{P}$} \\
\hline & \multicolumn{2}{|c|}{ Média } & & \\
\hline Peso inicial $(\mathrm{g})$ & 0,71 & 0,73 & 8,4 & $\mathrm{P}>0,05$ \\
\hline Peso final (g) & 2,81 & 2,77 & 24,91 & $P>0,05$ \\
\hline Comprimento total $(\mathrm{cm})$ & 4,95 & 5,15 & 8,1 & $\mathrm{P}>0,05$ \\
\hline Comprimento padrão (cm) & 4,03 & 4,04 & 9,92 & $\mathrm{P}>0,05$ \\
\hline Ganho de peso (g) & 2,08 & 2,04 & 33,65 & $\mathrm{P}>0,05$ \\
\hline Ganho de peso diário (g.dia $\left.{ }^{-1}\right)$ & 0,07 & 0,07 & 14,28 & $\mathrm{P}>0,05$ \\
\hline Ganho de crescimento diário $\left(\mathrm{cm} \cdot \mathrm{dia}^{-1}\right)$ & 0,02 & 0,051 & 0,5 & $\mathrm{P}>0,05$ \\
\hline Consumo diário de ração & 4,48 & 4,05 & 7,59 & $\mathrm{P}>0,05$ \\
\hline Conversão alimentar aparente & 2,5 & 2,4 & 30,0 & $\mathrm{P}>0,05$ \\
\hline Consumo de proteína bruta & 0,131 & 0,112 & 8,92 & $\mathrm{P}>0,05$ \\
\hline Taxa de eficiência da proteína bruta & 0,538 & 0,606 & 44,26 & $\mathrm{P}>0,05$ \\
\hline Índice hepatossomático (mg) & 2,46 & 2,57 & 0,4 & $\mathrm{P}>0,05$ \\
\hline Sobrevivência (\%) & 80 & 83,3 & 12,0 & $\mathrm{P}>0,05$ \\
\hline
\end{tabular}

Valores de $\mathrm{P}$ maiores que 0,05 não diferem estatisticamente a 5\% de significância $(\mathrm{P}>0,05)$.

Nesse experimento não houve efeito significativo $(\mathrm{P}>0,05)$ para a taxa de eficiência proteica (Tabela 3). Os peixes que consumiram ração com probiótico conseguiram superar o desafio do meio e se equipararam ao grupo controle. Isso mostra que os peixes que estavam submetidos ao desafio sanitário consumiram ração similar aos peixes do tratamento controle aproveitando melhor a proteína bruta devido à atuação de probiótico, garantindo que esses animais apresentassem uma maior sobrevivência.
Não houve efeito significativo $(\mathrm{P}>0,05)$ de sobrevivência e índice hepatosomático (Tabela 3). Raida et al. (2003), demonstraram que a administração de vários produtos microbianos nas dietas para peixes em sistema de criação proporcionam maior sobrevivência quando expostos a diversos patógenos.

Esse experimento mostra que podemos cultivar pós-larvas de tilápias-do-nilo em água representando um ambiente desafiador aos peixes e encontrar valores de desempenho similares a aqueles que são encontrados em animais que são cultivados em água com os parâmetros 
físico-químicos adequados desde sejam adicionadas cepas pribióticas. Sendo assim se torna vantajoso a utilização de probiótico no cultivo de peixes, pois, o mesmo ajuda os peixes a superarem a condição de estresse ao qual são submetidos, consumindo menos ração e se equiparando aos peixes cultivados em água sem desafio sanitário.

Meurer et al. (2008) não observaram efeito da levedura como probiótico na reversão sexual de tilápias quanto ao peso, comprimento e sobrevivência, devido possivelmente ao baixo desafio sanitário proporcionado aos peixes.

Mello et al. (2013) ao utilizar cepas probióticas (Bacillus cereus e Bacillus subtilis) em dietas de juvenis de tilápiasdo-nilo obtiveram um percentual de sobrevivência maior $(87,49 \%)$ em relação a um grupo controle sem a adição de probiótico, não apresentando ambiente desafiador aos animal, resultados semelhantes encontrados no experimento. Os resultados para ganho de peso, ganho de comprimento e sobrevivência estão de acordo com os encontrados por Meurer et al. (2007) ao testarem a inclusão de $S$. cerevisiae em rações para tilápia-do-nilo durante a fase de reversão sexual. Esses resultados são similares aos encontrados por Tachibana et al. (2011) ao utilizar diferentes níveis de probiótico $(0,5 \mathrm{e}$ $\left.10 \mathrm{mg} \cdot \mathrm{kg}^{-1}\right)$ na alimentação de tilápiasdo-nilo durante a inversão sexual, em que não observou diferença estatística $(\mathrm{P}>0,05)$ quanto ao parâmetro taxa de crescimento específico.

Os peixes alimentados com ração contendo probiótico apresentaram um ganho de peso similar aos animais do grupo controle, superando o desafio imposto aos animais. Já Castro \& Cervon (2004) obtiveram incremento no peso em tratamentos com probiótico (Saccharomyces cerevisiae) em tilápiasdo-nilo ao serem submetidos a um ambiente desafiador. Diferentemente, Carvalho et al. (2011) ao avaliarem a aplicação do probiótico à base de Bacillus subtilis ou mananoligossacarídeo em rações para alevinos de tilápias-do-nilo, não observaram diferenças estatísticas $(\mathrm{P}>0,05)$ para o parâmetro ganho de peso. Tal fato pode ser explicado pela falta de desafio proposto pelo meio aquícola.

Em relação ao parâmetro de conversão alimentar aparente não existiu diferença significativa $(\mathrm{P}>0,5)$. A conversão alimentar encontrada foi superior a observada por Monteiro et al. (2011) ao avaliar tilápias-do-nilo em esgoto doméstico tratado. Albuquerque et al. (2013) ao testarem o probiótico contendo contendo Bacillus cereus e o Bacillus subtilis C-3102 em tilápias durante a reversão sexual, também constataram que não houve diferenças para esse parâmetro.

Os valores encontrados do índice hepatossomático nos tratamentos observados foram maiores que os encontrados por Faria et al. (2001) em virtude do elevado teor de PB (35\%), já que esses autores trabalharam com níveis de até $20 \%$ na dieta (IHS $=1,30$ ). O elevado valor encontrado está relacionado ao estado nutricional dos peixes, confirmando a teoria de que o fígado pode reter ou gastar sua fonte lipídica (BUSACKER et al., 1990). Quanto maior, mais elevada será sua carga de trabalho, consequentemente ficará hipertrófico. Meurer et al. (2009) constataram diferença estatística para esse parâmetro ao testarem o uso de probiótico com levedura na alimentação de tilápias-do-nilo, durante a fase de reversão sexual, cultivadas em água de cultivo.

$\mathrm{O}$ uso de $1 \mathrm{~g}^{\mathrm{kg}}{ }^{-1}$ de probiótico (Saccharomyces cerevisiae) na ração de pós-larvas de tilápias-do-nilo cultivadas em água sob desafio sanitário 
Rev. Bras. Saúde Prod. Anim., Salvador, v.16, n.2, p.430-439 abr./jun.., 2015 http://www.rbspa.ufba.br ISSN 15199940

proporcionou melhorias no desempenho, sobrevivência e índice hepatossomático.

\section{REFERÊNCIAS}

ALBUQUERQUE, D.M.; MARENGONI, N.G.; BOSCOLO, W.R.; RIBEIRO, R.P.; MAHL, I.; MOURA, M.C. Probióticos em dietas para tilápia do Nilo durante a reversão sexual. Ciência Rural, v.43, n.8, p.1503-1508, 2013.

BALCAZAR, J.L.; VENDREL, L.D.; BLAS, I. Characterization of probiotic properties of lactic acid bacteria isolated from intestinal microbiota of fish. Aquaculture, v.278, n.1-4, p.188-191, 2008.

BORQUEZ, R.; TOLEDO, N. Drying and Storage Stability of a Probiotic Strain Incorporated into a Fish Feed Formulation. Drying Technology, v.28, n.4, p.508-516, 2010.

BRASIL. Ministério da Pesca e Aquicultura. Boletim Estatístico da Pesca e Aquicultura. 2010. Disponível em:

$<$ http://www.mpa.gov.br/index.php?opti on $=$ com_content\&view $=$ article $\& i d=300$ :bolet m-estatistico-da-pesca-eaquicultura-

2010\& catid $=7 \&$ Itemid $=303>$. Acesso em: 05 out. 2014.

BUSACKER, G.P.; ADELMN, I.R.; GOLISH, E.M. Growth. In: SCHECK, C.B.; MOYLE, P.B. (Eds). Method for fish biology. Bethesda, MD: American Fisheries Society, 1990. p.363-388.

CARVALHO, J.V.; LIRA, A.D.; COSTA, D.S.P.; MOREIRA, E.L.T.; PINTO, L.F.B.; ABREU, R.D.; ALBINATI, R.C.B. Desempenho zootécnico e morfometria intestinal de alevinos de tilápia-do -Nilo alimentados com Bacillus subtilis ou mananoligossacarídeo. Revista Brasileira de Saúde e Produção Animal [online], v.12, n.1, p.176-187, 2011.

CASTRO, C.A.S.; CERVON, M.F. Efecto del probiótico Saccharomyces cerevisiae em tilápia nilótica (Oreochromis niloticus) al ser proposto como promotor de crescimento. Revista Electrónica de Veterinária, v.4, n.2, p.113, 2004.

DHARMARAJ, S.; DHEVENDARAN, K. Evaluation of Streptomyces as a Probiotic Feed for the Growth of Ornamental Fish Xiphophorus helleri. Technology and Biotechnology, v.48, n.4, p.497-504, 2010.

EMPRESA BRASILEIRA DE PESQUISA AGROPECUÁRIA EMBRAPA. Centro Nacional de Pesquisa de Solos. Manual de métodos de análise de solo. Brasília: EMBRAPASPI; EMBRAPA-CNPS, 1997. 212p.

FARIA, A.C.E.A.; HAYASHI, C.; GALDIOLI, E.M.; SOARES, C.M. Farinha de peixe em rações para alevinos de tilápia do Nilo, Oreochromis niloticus (L.), linhagem tailandesa. Acta Scientiarum, v.23, n.4, p.903-908, 2001.

FLORES, M.L.; NOVOA, M.A.O.; MENDEZ, B.E.G.; MADRID, W.L. Use of the bactéria Streptococcus faecium and Lactobacillus acidophilus, and the yeast Saccharomyces cerevisae as growth promoters in Nile tilapia (Oreochromis niloticus). Aquaculture, v.216, p.193-201, 2003.

GATESOUPE, F.J. Updating the importance of lactic acid bacteria in fish farming: Natural occurrence and 
Rev. Bras. Saúde Prod. Anim., Salvador, v.16, n.2, p.430-439 abr./jun.., 2015 http://www.rbspa.ufba.br ISSN 15199940

probiotic treatments. Journal of

Molecular Microbiology and

Biotechnology, v.14, n.1-3, p.107-114, 2008.

GRAM, L.; PROL, M.J; BRUHN, J. B.

Real-time PCR detection and quantification of fish probiotic Phaeobacter strain 27-4 and fish pathogenic Vibrio in microalgae, rotifer, Artemia and first feeding turbot (Psetta maxima) larvae. Journal of Applied Microbiology, v.106, n.4, p.1292-1303, 2009.

KESARCODI WATSON, A.; KASPAR, H.; LATEGAN, M. J.; GIBSON, L. Probiotics in aquaculture: The need, principles and mechanisms of action and screening processes.

Aquaculture, v.274, p.1-14, 2008.

KUBITZA, L.M.M. Tilápias: qualidade da água, sistemas de cultivo, planejamento da produção, manejo nutricional e alimentar e sanidade Parte 2". Revista Panorama da Aqüicultura, v. 60, n.10, p.31-53, 2000.

LIMA, A.C.F.; PIZAURO JR., J.M.; MACARI, M.; MALHEIROS, E.B. Efeito do uso de probiótico sobre o desempenho e atividade de enzimas digestivas de frangos de corte. Revista Brasileira de Zootecnia, v.32, n.1, p.200-207, 2003.

MELLO, H.; MORAES, J.R.E.; NIZA, I.G.; MORAES, F.R.; OZÓRIO, R.O.A.; SHIMADA, M.T.; ENGRACIA FILHO, J.R.; CLAUDIANO, G.S. Efeitos benéficos de probióticos no intestino de juvenis de Tilápia-do-Nilo. Pesquisa Veterinária Brasileira, v.33, n.6, p.724-730, 2013.
MONTEIRO, C.A.B.; SANTOS, A.B.; SANTOS, E.S.; ARARIPE, M.N.B.A.; MOTA, S. Efeito da aeração por air-lift na alevinagem de tilápias de Tilápia-doNilo em esgoto doméstico tratado.

Revista DAE, v.186, p.16-22, 2011.

MEURER, F.F.; HAYASHI, C.C; COSTA, M.M.; MASCIOLI, A.S.S; COLPINI, L.M.S.S.O; FRECCIA, A.A. Levedura como p probiótico probiótico na reversão sexual da tilápia-do-Nilo.

Revista Brasileira de Saúde e Produção Animal [online], v.9, n.4, p.80-804-812, 2008.

MEURER, F.; HAYASHI, C.; COSTA, M.M.; FRECCIA, A.;MAUERWERK, M.T. Saccharomyces cerevisiae como probiótico para alevinos de tilápia-donilo submetidos a desafio sanitário.

Revista Brasileira de Zootecnia, v.36, n.5, p.1219-1224, 2007.

PROENÇA, C.E.M. de; BITTENCOURT, P.R.L. Manual de Piscicultura Tropical. Brasilia: IBAMA, 1994.

RAIDA, M.K.; LARSEN, J.L.; NILSEN, M.E.; BUCHMANN, K. Enhanced resistance of rainbow trout, Oncorhynchus mykiss (Walbaum), against Yersinia ruckeri challenge following oral administration of Bacillus subtilis and B. licheniformis (BIOPLUS2B). Journal of Fish Diseases, v.26, p.495-498, 2003.

SANTOS, E.S.; OLIVEIRA, M.A.; MOTA, S.; AQUINO, M.D.; VASCONCELOS, M.M. Crescimento e qualidade dos alevinos de tilápia-doNilo produzidos em esgoto doméstico tratado. Revista Ciência Agronômica, v.40, n.2, p.232-239, 2009a. 
Rev. Bras. Saúde Prod. Anim., Salvador, v.16, n.2, p.430-439 abr./jun.., 2015 http://www.rbspa.ufba.br

SANTOS, E.S.; M, F.N.; MOTA. S.;

SANTOS, A.B.; AQUINO, M.D.

Cultivo de tilápia-do-nilo em esgoto doméstico tratado, com diferentes taxas de alimentação. Revista DAE, v.180, p.4-11, 2009b.

STATISTICAL ANALYSIS

SYSTEMS - SAS. SAS OnlineDoc ${ }^{\circledR}$. Version 8. Cary, NC: SAS Institute Inc., 2003.

TACHIBANA, L.; DIAS, D.C.; MASSATOSHI ISHIKAWA, C.; CORRÊA, C.F.; LEONARDO, A.F.G.; RANZANI-PAIVA, M.J.T. Probiótico na alimentação da tilápia-do-Nilo (Oreochromis niloticus Linnaeus, 1758), durante a inversão sexual: desempenho zootécnico e recuperação da bactéria probiótica intestinal.

Bioikos, v.25, n.1, p.25-31, 2011.

ZHOU, Q.; LI, K.; JUN, X.; BO, L.

Role and functions of beneficial microorganisms in sustainable aquaculture.

Bioresource Technology, v.100, p.3780-3786, 2009.

Data de recebimento: $21 / 07 / 2014$

Data de aprovação: 18/03/2015 